Shannon Wu, BA

Cleveland Clinic Lerner College of

Medicine of Case Western Reserve

University, Cleveland, Ohio
Demetrius M. Coombs, MD Resident Physician, Department of Plastic Surgery, Dermatology and Plastic Surgery Institute, Cleveland Clinic, Cleveland, Ohio
Raffi Gurunian, MD, PhD

Staff Surgeon, Department of Plastic Surgery,

Dermatology and Plastic Surgery Institute,

Cleveland Clinic; Professor, Cleveland Clinic

Lerner College of Medicine of Case Western

Reserve University, Cleveland, Ohio

\title{
Liposuction:
}

\section{Concepts, safety, and techniques in body-contouring surgery}

\section{ABSTRACT}

Liposuction is the second most commonly performed cosmetic surgery in the United States and the most common surgical procedure in patients between the ages of 35 and 64; practitioners of medicine and surgery will undoubtedly encounter these patients in their practice. This brief review discusses the role of liposuction and fat transfer in aesthetic and reconstructive surgery, as well as key considerations, indications, and safety concerns.

\section{KEY POINTS}

The most common area for fat removal is between the inframammary fold and gluteal fold - namely, the abdomen, flanks, trochanteric region, lumbar region, and gluteal region.

Liposuction is increasingly being used as an adjunct to enhance other aesthetic procedures such as breast augmentation, cervicoplasty, abdominoplasty, gluteal fat transfer, and body contouring after bariatric surgery.

Gluteal fat transfer, popularly called the "Brazilian butt lift," is an application of liposuction in which large volumes of fat are transferred from an undesirable area, such as the abdomen or inner thighs, to the buttocks.

Noncosmetic indications include management of lipomas, lipedema, and lipodystrophy syndromes.

The most common complication is contour deformity.

doi:10.3949/ccjm.87a.19097
\ UCTION-ASSISTED LIPECTOMY, more com $\checkmark$ monly known as liposuction, is an outpatient procedure that removes adipose tissue from the subcutaneous space with the goal of achieving a more desirable body contour. It is the second most commonly performed cosmetic surgery in the United States and the most common surgical procedure in patients between the ages of 35 and $64 .{ }^{1}$ In 2018, surgeons performed 258,558 liposuction procedures, a 5\% increase from 2017. ${ }^{2}$ The number of liposuction procedures increased 124\% from 1997 to $2015^{3}$

Liposuction is advantageous in that the removal of fat cells limits future deposition of fat in those areas. ${ }^{4}$ Ultimately, liposuction allows plastic surgeons to semipermanently redistribute volume in accordance with a patient's ideal, and with lower complication, morbidity, and mortality rates than with other surgical procedures.

In addition to its utility for purely aesthetic purposes, liposuction is an important adjunct in reconstructive surgery, particularly of the breast and face, when harvested fat is autologously reinjected in these tissues. One particular procedure rising in popularity and gaining significant attention in the media is gluteal fat grafting.

This article provides a general overview of liposuction, including its history, current techniques, indications, and safety concerns.

\section{HISTORY}

The first attempt at fat removal was by Dujarrier in 1921, who operated on the knees and calves of a dancer. Injury to the femoral artery led to amputation of the leg. ${ }^{5}$ In 1964 , Schrudde cu- 


\section{Ideally,}

patients have

\section{adequate}

skin elasticity

and are within

$20 \%$ to $30 \%$

of their ideal

body weight
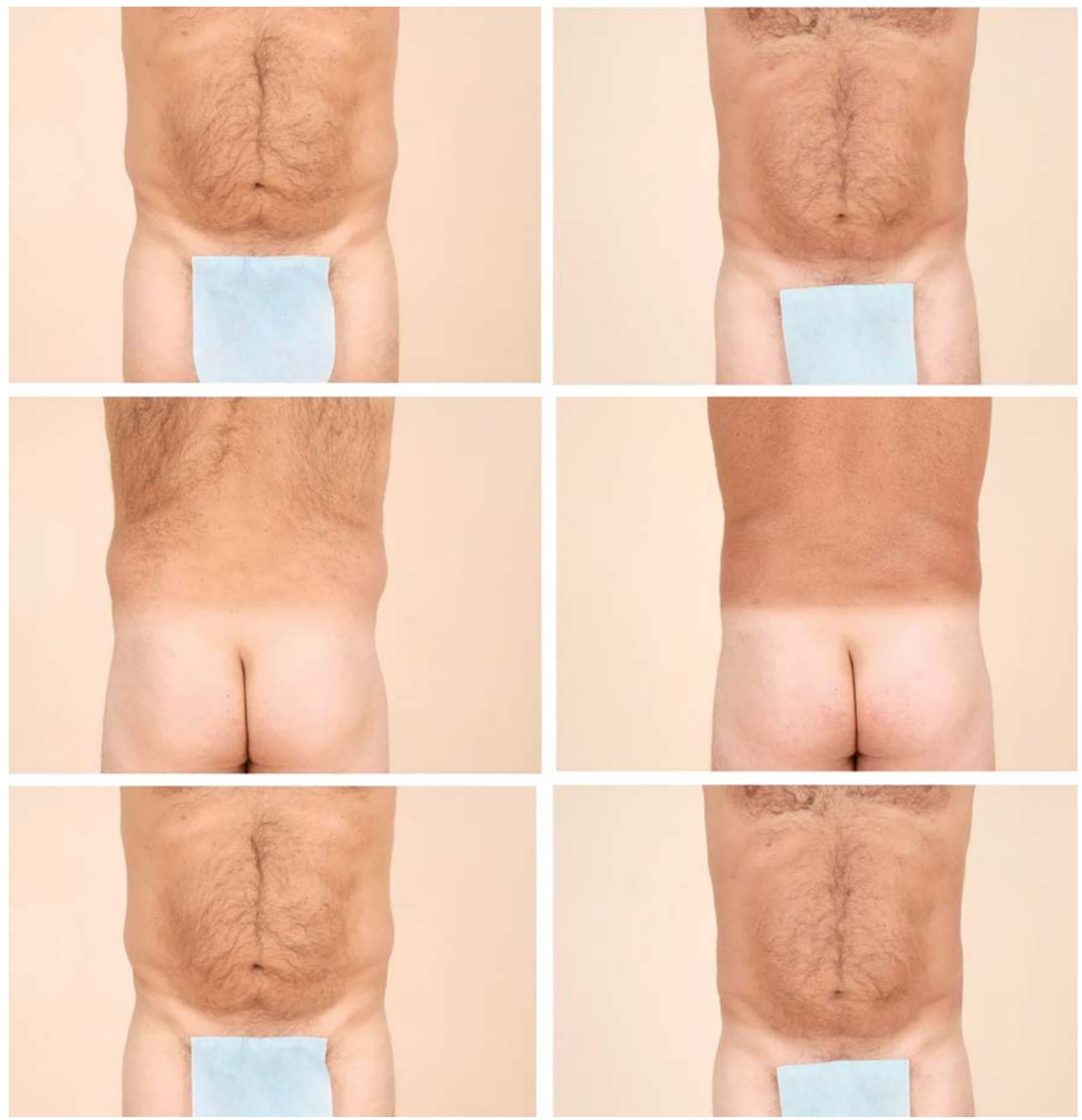

Figure 1. Left: Preoperative appearance of a 52-year-old man who presented for liposuction of localized adiposity within the abdomen and bilateral flanks. Right: The same patient 6 months later after removal of $1.4 \mathrm{~L}$ of adipose tissue.

retted subcutaneous fat from a patient's leg, but observed skin necrosis in 4 of 15 separate patients, in addition to hematoma and seroma. ${ }^{6}$

The era of modern liposuction began in 1975 when Arpad and Fischer pioneered the use of blunt hollow cannulas and suction curettage for liposuction on the outer thighs, but the patients ultimately experienced deforming lymphorrhea. ${ }^{7}$ An important milestone was reached in 1977 when Illouz developed the "wet technique," in which injection of hypo- tonic saline solution and hyaluronidase into adipose tissue before liposuction reduced hemorrhagic risk. ${ }^{8}$ This type of hydrodissection, similar to that used today, preserved neurovascular bundles and enlarged the deep adipose layer for easier aspiration.

In 1983, Fournier used syringes instead of mechanical suction for better control of negative pressure. $^{9}$ By 1987, Klein had developed the tumescent technique-a type of local anesthesia infiltration that permitted the re- 
moval of larger volumes of fat while reducing bleeding. ${ }^{10}$ Toledo expanded the use of syringes to include various gauges and sizes for aspiration of adipose tissue in $1988 .{ }^{11}$

In the early 1990s, the development of ultrasonographically guided liposuction by Zocchi expanded the use of liposuction for previously unfavorable, fibrous areas such as the buttocks. ${ }^{12,13}$ The development of minimally invasive, laser-assisted liposuction by Apfelberg, also in 1992, prevented destruction of neurovascular structures by cannulas and promoted tissue tightening for an aesthetic result. ${ }^{14}$ Recently, the development of powerassisted liposuction has further expanded and improved this procedure, increasing the popularity and use of liposuction. ${ }^{15}$

\section{COSMETIC INDICATIONS}

Liposuction is used to achieve body contouring by removing excess fat deposits in undesirable areas of the body. Fat is suctioned from demarcated areas in the body amenable to contouring.

The most common area for fat removal is between the inframammary fold and gluteal fold-namely, the abdomen, flanks, trochanteric region, lumbar region, and gluteal region (Figure 1). Other areas of fat removal include the breasts (eg, breast reduction surgery), thighs, and calves.

The site of incision is an important anatomic consideration, and the surgeon should select regions where the surgical scar, although modest, can be hidden by clothing, as well as locations conducive to broad fanning of the cannula during the procedure.

There are 5 zones in which superficial subcutaneous tissues adhere to underlying deep fascia of muscle: the lateral gluteal depression, gluteal crease, distal posterior thigh, midmedial thigh, and inferolateral iliotibial tract. Because these zones define the natural shape of the body, suctioning from these areas increases the risk of contour deformities. ${ }^{16}$ Ideally, patients have adequate skin elasticity and are within $20 \%$ to $30 \%$ of their ideal body weight to achieve desired aesthetic outcomes. ${ }^{17}$

Liposuction is also increasingly being used as an adjunct to enhance other aesthetic procedures such as breast augmentation, cervicoplasty, abdominoplasty, gluteal fat transfer, and body contouring for postsurgical bariatric patients (Figure 2 and Figure 3). ${ }^{18}$ Liposuction can also be used to promote gender-specific features. ${ }^{19}$ In women, the goals of liposuction are to promote shapely contours of the breasts, waist, hip, and buttocks. In men, liposuction aims to achieve upper body dominance, such as removing excess flank adipose tissue ("love handles").

\section{GLUTEAL FAT TRANSFER}

Gluteal fat transfer, popularly called the "Brazilian butt lift," is an application of liposuction in which large volumes of fat are transferred from an undesirable area, such as the abdomen or inner thighs, to the buttocks. ${ }^{20}$ Fat is first removed by liposuction (the volume of which varies widely and remains largely based upon the patient's preoperative anatomy) and is then used to augment the contour of the buttocks commensurate with the patient's desires and anatomic deficiencies. ${ }^{21,22}$

High-volume fat transfer, defined as a volume greater than 1,000 $\mathrm{mL}$ per buttock, has historically been associated with a higher risk of infection at the graft site and seroma formation at the harvested site. Newer evidence suggests high-volume buttock fat transfer may be safe and effective with proper technique. ${ }^{23}$ Thus, the contour is improved in both the donor region, such as the waist, and the recipient region.

The popularity of gluteal fat transfer is rapidly increasing due to shifting beauty standards in American culture and attention from celebrity figures. More than 26,000 gluteal fat transfer procedures were performed in 2018, a $16 \%$ increase from the previous year, and a 132\% increase from 2013.,24 However, reports of fatal pulmonary fat embolisms following injury to gluteal veins and an estimated mortality rate of 1 in 3,000 from this procedure warrant continued investigation about its safety and ideal technique. ${ }^{25}$

The Multi-Society Gluteal Fat Grafting Task Force ${ }^{26}$ was established to investigate and improve patient safety of this procedure, and current research including anatomic studies as well as educational symposia are ongoing. Risks and alternative methods such as gluteal implants must be discussed with the patient

\section{More than 26,000 gluteal fat transfer procedures were performed in 2018}


Fat harvested in liposuction can be used to 'lipofill' in breast reconstruction, burns, and scars before this procedure. Moreover, as with any aesthetic or reconstructive procedure, the American Society of Plastic Surgeons recommends that patients seek consultation from a board-certified plastic surgeon.

\section{NONCOSMETIC INDICATIONS}

Liposuction is also being used for reconstructive purposes, including management of the following disorders:

- Lipomas and angiolipomas, with minimal to no scarring

- Lipedema, in which subcutaneous fat deposition in the lower limbs can interfere with daily activities such as walking; in these patients, liposuction can improve mobility ${ }^{27}$

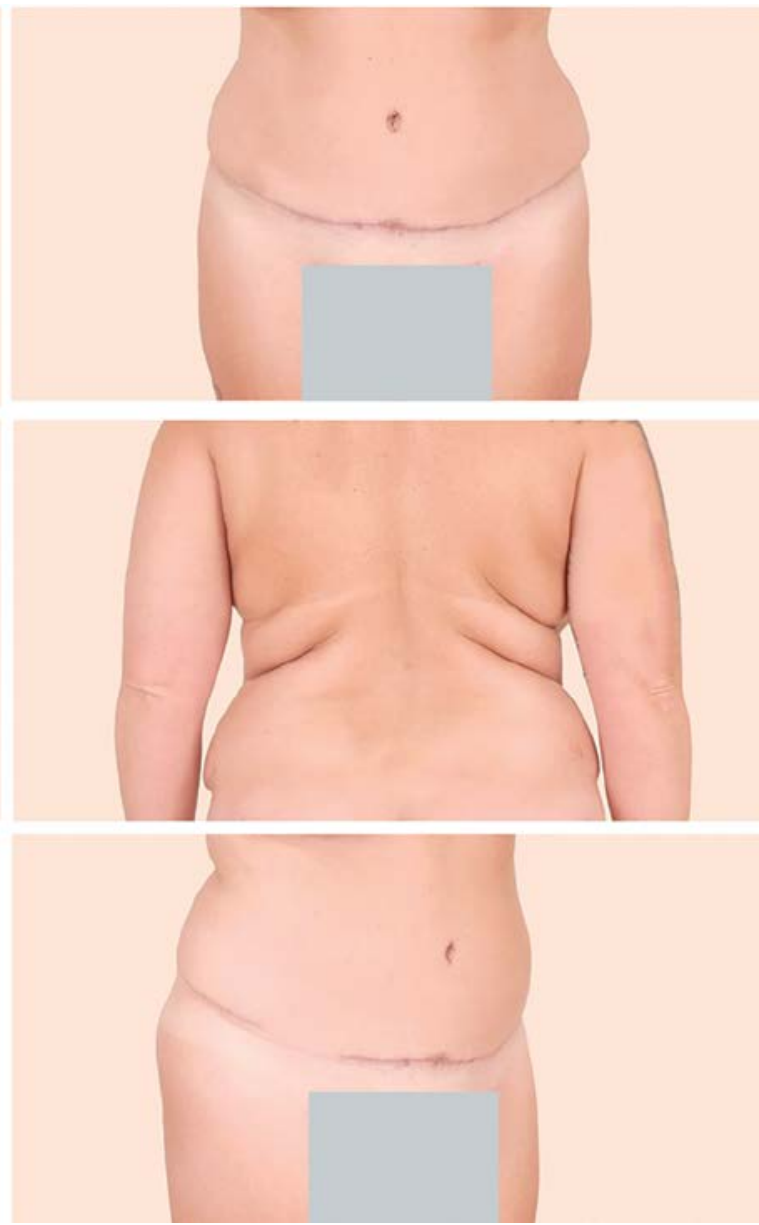

Figure 2. Left: A 38-year-old woman who presented with excess skin and adiposity of the Therior abdomen and excess adipose tissue in the bilateral upper back and hips. Right: 列 bilateral upper back and hip areas (with a total of $2 \mathrm{~L}$ of tissue removed), illustrating that these procedures may be combined safely and yield satisfying results.

- Lymphedema, particularly if it is refractory to traditional conservative treatments

- Lipodystrophy syndromes, which are congenital or acquired diseases of fat atrophy; liposuction with autologous fat transfer can replace loss of fat in areas such as the feet or buttocks to relieve physical discomfort ${ }^{28}$

- Cervicodorsal lipodystrophy associated with Cushing syndrome and use of HIV medications ${ }^{29}$

- Gynecomastia in men and macromastia in women, in conjunction with mammoplasty. Additionally, liposuction can be used to:

- Reduce excess fat deposits at surgical sites in obese patients who are undergoing tracheostomy, colostomy, or urostomy procedures 


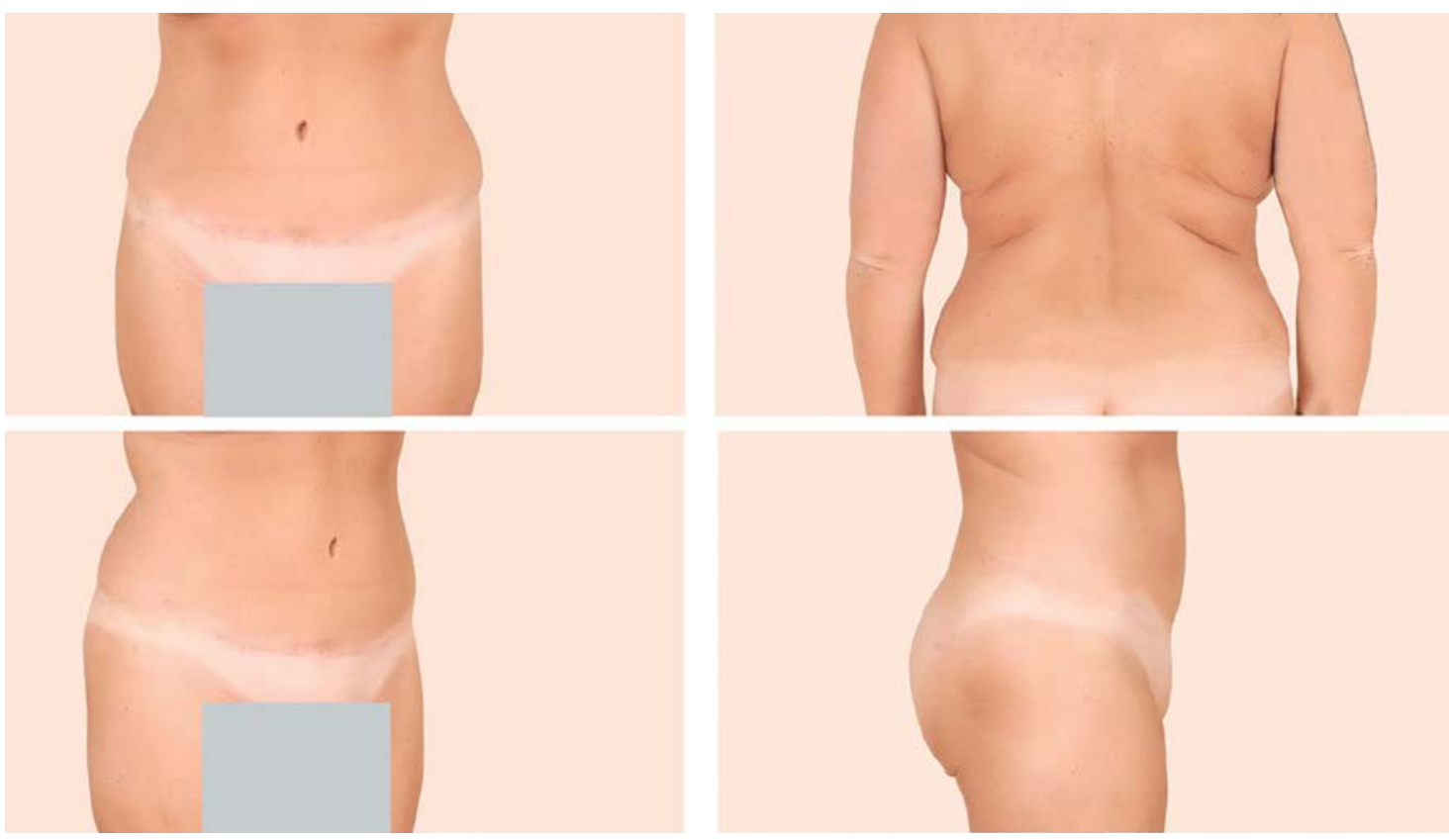

Figure 3. The same patient from Figure 2, now almost 19 months after surgery but having lost weight, demonstrating stable long-term results after abdominoplasty and liposuction. Note the stable improvement in bilateral flank and upper-back adiposity.

- Reduce the amount of subcutaneous fat in flaps created for reconstructive procedures, thereby improving aesthetic results

- Collect harvested fat to "lipofill" in breast reconstruction, burns, and scars because adult adipose-derived stem cells are contained therein. ${ }^{30}$

Although no absolute contraindications exist for liposuction, relative contraindications should be considered during the patient evaluation. ${ }^{31}$ Anticoagulants and medications that interfere with lidocaine metabolism should be stopped before liposuction. ${ }^{32}$ Poor skin firmness and elasticity in elderly patients would lead to poor skin draping postoperatively and potentially increase patient dissatisfaction.

Further, reasonable expectations must be established, and patients with body dysmorphic disorder may require a psychiatric consultation before surgery. Patients with diabetes mellitus, cardiac disease, and liver disease may need medical clearance before surgery at the discretion of both the surgeon and the facility where the procedure is to take place. Lastly, as has been discussed elsewhere in the surgical literature, poorly controlled diabetes increases the risk of infection.

\section{TECHNIQUES}

The most common technique remains the traditional suction-assisted lipectomy (Table 1). ${ }^{33-36}$ Small-volume liposuction procedures in which a maximum of $1,000 \mathrm{~mL}$ of fat is removed can be performed with local anesthesia. Although there is no maximum volume of fat that can be removed in a single setting, the risk for seroma and fluid imbalance increases along with the volume of fat that is removed.

Megaliposuction, a procedure in which an amount greater than 10\% of body weight is removed, can be safely performed by an experienced surgeon. Large-volume liposuction procedures should be performed with general anesthesia. ${ }^{19}$ Harvested fat may be used for subsequent fat transfer. ${ }^{19}$

The advantages of liposuction are short surgery time (typically under 3 hours, depending on the extent of fat removal) and concomitant procedures. In addition, patients undergoing liposuction have a short recovery period, unobtrusive scars, permanent results, low complication rates, and low morbidity and mortality rates relative to other surgical procedures. Because adipocytes are removed, further storage of fat in those areas is limited,
The most common technique is traditional suctionassisted lipectomy 


\section{TABLE 1}

\section{Liposuction techniques}

\section{Suction-assisted lipectomy}

Negative pressure from a syringe applied to a small- volume, blunt-tip suction cannula is used to remove fat..$^{29}$ Suctioning from the superficial layer should be avoided to prevent dimpling, hyperpigmentation, and contour irregularities. ${ }^{19}$ The superficial fat layer contains vertical fibrous septa, which would result in contour deformities if disrupted; however, exploitation of this anatomy with the liposuction cannula, also known as abdominal etching, has been demonstrated to produce highly defined abdominal aesthetic contours (eg, "6-pack abs"). ${ }^{33}$

\section{Ultrasound-assisted lipectomy}

Transmitting ultrasound energy to emulsify fat prior to its removal, ${ }^{34}$ ultrasonographically assisted lipectomy (UAL) can be advantageous in fibrous areas, such as the back, chest, and upper flank, that are more difficult to target in standard liposuction. UAL has shown marked benefit in treatment of gynecomastia. However, larger incisions are required in UAL and operations require more time. There is an increased risk of thermal injury to subdermal tissues due to the exothermic energy caused by ultrasound.

\section{Laser-assisted lipectomy}

Laser-assisted lipectomy (LAL) is performed by inserting a laser fiber via a small incision. ${ }^{35}$ Although complications of LAL are rare, 1 study observed a complication rate of $0.93 \%$ that included skin burns and a local infection. ${ }^{36}$

\section{Power-assisted lipectomy}

Power-assisted lipectomy is performed with an external power source, typically an electric vacuum pump. ${ }^{35}$ This technique can be advantageous for large volumes of tissue removal and in densely fibrous areas, as the power assistance reduces operator fatigue.

leading to high patient satisfaction with longterm results. ${ }^{37}$

More research is needed to determine the degree of fat reaccumulation in the treated area and redistribution to nontreated areas. ${ }^{38,39}$ As expected, weight gain can still occur, and the patient should be advised to maintain a well-balanced diet and exercise regimen.

\section{RISK FACTORS}

Patients with cardiovascular disease, pulmonary disease, diabetes, and vascular disease face a greater risk with this procedure. Tobacco use is a risk factor for surgical complications. ${ }^{40,41}$ Ongoing infections before the procedure, particularly near the area of the liposuction site (eg, cellulitis), would require treatment with antibiotics and resolution of infection before surgery. Previous venous thromboembolism, eg, pulmonary embolism, may also increase the risk of surgical complications.

\section{COMPLICATIONS}

Complications are relatively uncommon in liposuction and of low risk relative to other procedures. ${ }^{42}$ In one study, the overall complication rate was $2.4 \%{ }^{43}$ The complication rate was higher $(3.5 \%)$ when liposuction was combined with other procedures, whereas liposuction as a solitary procedure had a complication rate of only $0.7 \%{ }^{41}$ Complications include ecchymosis, edema, surgical site infection, seroma, hematoma, and venous thromboembolism (Table 2). ${ }^{43}$

The most common complication of liposuction is contour deformity. As many as $9 \%$ of patients may report soft-tissue depressions or elevations, skin panniculus, folds, or wrinkles. ${ }^{44}$ Contour deformities can be prevented by using smaller diameter cannulas, avoiding suctioning from superficial layers, employing a "crisscrossing" technique, and allowing slight undercorrection for postoperative fat lysis. ${ }^{45}$

Seroma and hematoma are also rare complications of liposuction. ${ }^{46}$ Seromas, which are collections of serous fluid resulting from breakdown of the fibrous tissue network, may develop from initial blind cannula injury to small perforating vessels or lymphatic vessels. ${ }^{31}$ Use of progressive tension sutures-primarily a technique to address dead space in surgeries such as abdominoplasty ("tummytuck")- has been shown to reduce the rate of seroma from $9 \%$ to $2 \% .46$

Wound infection is reported in fewer than $3 \%$ of inpatient liposuction cases and in approximately $1 \%$ in outpatient surgeries ${ }^{47}$ Low infection rates can be attributed to surgeon expertise, proper prophylactic antibiotics, and sterile technique, among other factors. Although uncommon, early-stage wound infections (ie, cellulitis) may develop into more severe sepsis or necrotizing fasciitis-the latter of which is a surgical emergency. ${ }^{48}$

A 2018 study estimated that after liposuction with or without subsequent fat grafting, at least 17 patients have experienced clinically significant fat embolization, or fat embolization syndrome. ${ }^{49}$ However, more recent data suggests that worldwide, fatal and nonfatal fat 
embolism, particularly after gluteal fat grafting, may exceed 135 cases. $^{50}$

Although fat embolism is rare, its mortality rate of $10 \%$ to $15 \%$ warrants careful postoperative monitoring for rapid detection and treatment, and it has been reported to occur within 12 to 72 hours after surgery. ${ }^{50,51}$ As described, gluteal fat transfer is the only procedure with a higher risk of fatal fat embolism, and is still considered to have the highest mortality rate of any aesthetic procedure..$^{52}$

The incidence of venous thromboembolic events (deep venous thrombosis and pulmonary embolism) after liposuction is low at $0.03 \% .^{53,54}$ Pulmonary embolism is the most common cause of death after this procedure, which carries an overall mortality rate of $0.01 \%{ }^{54}$ Sameday ambulation after liposuction surgery is encouraged to prevent thromboembolic events.

As with any surgical procedure, liposuction causes a transient elevation of acute inflammatory markers (interleukin 6, C-reactive protein), but there is no increased risk of progression to renal disease or chronic inflammation. ${ }^{55}$ Some studies suggest that, due to permanent removal of adipocytes, the long-term metabolic benefits of liposuction include improved insulin sensitivity and reduced inflammation. However, more studies are warranted. ${ }^{56}$

Systemic complications that arise weeks to months after surgery include edema, lymphedema, wound dehiscence, hypertrophic scar formation, ecchymosis, and skin laxity. Blind cannula injury can lead to abdominal wall injury, bowel perforation, or vessel injury. Although uncommon, skin devascularization and skin necrosis can occur if the surgeon suctions too closely to the skin undersurface and injures the dermal plexus. ${ }^{57}$

Breast augmentation with autologous fat transfer may lead to fat necrosis that mimics microcalcifications suspicious for breast cancer on mammographic imaging. ${ }^{58}$ However the incidence of these imaging findings is similar to those in patients without fat transfer, and thus, breast augmentation does not hinder detection of breast cancer.

\section{FUTURE DIRECTIONS}

Liposuction can improve body contour and reduce body mass index, and advances are con-
TABLE 2

\section{Complications of liposuction}

\section{Short-term complications}

Wound infection

Hematoma, seroma

Edema

Ecchymosis

Paresthesia

Fat embolism, pulmonary embolism

Skin necrosis

\section{Long-term complications}

Contour deformity

Hyperpigmentation

Hypertrophic scarring

Lymphedema

tinually being developed. Due to the benefits of long-term weight redistribution, low surgical risk, and short operation time, patients seeking body contour changes will continue to pursue liposuction. The long-term effects on metabolic sequelae such as insulin sensitivity are still being actively researched. ${ }^{59,60}$

Noncosmetic indications are also expanding, particularly fat grafting for breast, facial, and pedal reconstruction. ${ }^{61}$ Although liposuction can address a wide variety of needs spanning from cosmetic to reconstructive purposes, the procedure is rarely covered by Medicare or third-party insurance plans, even for issues that cause functional impairment. ${ }^{62}$

Research is being performed in noninvasive body contouring such as cryolipolysis, which may decrease subcutaneous fat deposits while providing dermal tightening with no surgical scars ${ }^{63,64}$ Cryolipolysis (CoolSculpting), deoxycholic acid subcutaneous injection (Kybella), and radiofrequency skin-tightening (Thermage) are nonsurgical volume-reduction and tissue-tightening procedures that address dissatisfaction with body contouring but remain beyond the scope of this manuscript. We mention them for the sake of completeness.
Approximately $1 \%$ of outpatient liposuction cases result in wound infection 


\section{LIPOSUCTION}

\section{REFERENCES}

1. De Souza MM, Jewell AD, Grief SN, Vail BA. Plastic surgery for women. Prim Care 2018; 45(4):705-717. doi:10.1016/j.pop.2018.07.008

2. American Society of Plastic Surgeons. 2018 National plastic surgery statistics report. Accessed March 16, 2020.

https://www.plasticsurgery.org/documents/News/Statistics/2018/ plastic-surgery-statistics-report-2018.pdf

3. The American Society for Aesthetic Plastic Surgery's Cosmetic Surgery National Data Bank: Statistics 2018. Aesthet Surg J 2019;39(suppl 4):1-27 doi:10.1093/asj/sjz164

4. Mohammed BS, Cohen S, Reeds D, Young VL, Klein S. Long-term effects of large-volume liposuction on metabolic risk factors for coronary heart disease. Obesity (Silver Spring) 2008; 16(12):2648-2651. doi:10.1038/oby.2008.418

5. Dolsky RL, Newman J, Fetzek JR, Anderson RW. Liposuction. History, techniques, and complications. Dermatol Clin 1987; 5(2):313-333. pmid:3555903

6. Weniger FG, Calvert JW, Newton ED. Liposuction of the legs and ankles: a review of the literature. Plast Reconstr Surg 2004; 113(6):1771-1785. doi:10.1097/01.prs.0000117299.55812.2e

7. Fischer G. Liposculpture: the "correct" history of liposuction. Part I. J Dermatol Surg Oncol 1990; 16(12):1087-1089. doi:10.1111/j.1524-4725.1990.tb00017.x

8. Illouz YG. Body contouring by lipolysis: a 5-year experience with over 3000 cases. Plast Reconstr Surg 1983; 72(5):591-597. doi:10.1097/00006534-198311000-00001

9. Fournier PF, Otteni FM. Lipodissection in body sculpturing: the dry procedure. Plast Reconstr Surg 1983; 72(5):598-609. doi:10.1097/00006534-198311000-00002

10. Klein JA. The tumescent technique for lipo-suction surgery. Am J Cosmetic Surg 1987; 4(4):263-267. doi:10.1177/074880688700400403

11. Toledo LS. Annals of the International Symposium Recent Advances in Plastic Surgery. São Paulo, Brazil: 1992.

12. Zocchi M. Ultrasonic liposculpturing. Aesthetic Plast Surg 1992; 16(4):287-298. doi:10.1007/bf01570690

13. Rohrich RJ, Beran SJ, Kenkel JM, Adams WP Jr, DiSpaltro F. Extending the role of liposuction in body contouring with ultrasoundassisted liposuction. Plast Reconstr Surg 1998; 101(4):1090-1102. doi:10.1097/00006534-199804040-00033

14. McBean JC, Katz BE. Laser lipolysis: an update. J Clin Aesthet Dermatol 2011; 4(7):25-34. pmid:21779417

15. Coleman WP 3rd. Powered liposuction. Dermatol Surg 2000; 26(4):315-318. doi:10.1046/j.1524-4725.2000.99240.x

16. Rohrich RJ, Smith PD, Marcantonio DR, Kenkel JM. The zones of adherence: role in minimizing and preventing contour deformities in liposuction. Plast Reconstr Surg 2001; 107(6):1562-1569. doi:10.1097/00006534-200105000-00043

17. Matarasso A, Hutchinson $\mathrm{OH}$. Liposuction. JAMA 2001; 285(3):266268. doi:10.1001/jama.285.3.266

18. Salibian AA, Frey JD, Bekisz JM, Choi M, Karp NS. Fat grafting and breast augmentation: a systematic review of primary composite augmentation. Plast Reconstr Surg Glob Open 2019; 7(7):e2340. doi:10.1097/GOX.0000000000002340

19. Tabbal GN, Ahmad J, Lista F, Rohrich RJ. Advances in liposuction: five key principles with emphasis on patient safety and outcomes. Plast Reconstr Surg Glob Open 2013; 1(8):e75. doi:10.1097/GOX.0000000000000007

20. Cárdenas-Camarena L, Arenas-Quintana R, Robles-Cervantes JA. Buttocks fat grafting: 14 years of evolution and experience. Plast Reconstr Surg 2011; 128(2):545-555. doi:10.1097/PRS.0b013e31821b640b

21. Swanson E. Prospective controlled study of buttock fat transfer using ultrasound and photographic measurements. Plast Reconstr Surg Glob Open 2016; 4(5):e697. doi:10.1097/GOX.0000000000000700

22. Chugay NV, Chugay PN, Shiffman MA. Buttocks augmentation. In: Body Sculpting with Silicone Implants. Switzerland: Springer Inter- national Publishing; 2014:140.

23. Pane TA. Experience with high-volume buttock fat transfer: a report of 137 cases. Aesthet Surg J 2019; 39(5):526-532. doi:10.1093/asj/sjy191

24. Cosmetic Surgery National Data Bank statistics. Aesthet Surg J 2014;34 Suppl 1:1-20. doi:10.1093/asj/34.Supplement_1.1.

25. Mofid MM, Teitelbaum S, Suissa D, et al. Report on mortality from gluteal fat grafting: recommendations from the ASERF Task Force. Aesthet Surg J 2017; 37(7):796-806. doi:10.1093/asj/sjx004

26. Mills D, Rubin JP, Saltz r. Multi-society gluteal fat grafting task force issues safety advisory urging practitioners to reevaluate technique. Accessed May 12, 2020. https://www.surgery.org/sites/default/files/ Gluteal-Fat-Grafting-02-06-18_0.pdf

27. Atiyeh B, Costagliola M, Illouz YG, Dibo S, Zgheib E, Rampillon F. Functional and therapeutic indications of liposuction: personal experience and review of the literature. Ann Plast Surg 2015; 75(2):231-245. doi:10.1097/SAP.0000000000000055

28. Brown RJ, Araujo-Vilar D, Cheung PT, et al. The diagnosis and management of lipodystrophy syndromes: a multi-society practice guideline. J Clin Endocrinol Metab 2016; 101(12):4500-4511. doi:10.1210/jc.2016-2466

29. Bellini E, Grieco MP, Raposio E. A journey through liposuction and liposculture: review. Ann Med Surg (Lond) 2017; 24:53-60. doi:10.1016/j.amsu.2017.10.024

30. Zuk PA, Zhu M, Mizuno H, et al. Multilineage cells from human adipose tissue: implications for cell-based therapies. Tissue Eng 2001; 7(2):211-228. doi:10.1089/107632701300062859

31. Almutairi K, Gusenoff JA, Rubin JP. Body contouring. Plast Reconstr Surg 2016; 137(3):586e-602e. doi:10.1097/PRS.0000000000002140.

32. Marwah M, Kulkarni A, Godse K, Abhyankar S, Patil S, Nadkarni N. Fat ful'fill'ment: a review of autologous fat grafting. J Cutan Aesthet Surg 2013; 6(3):132-138. doi:10.4103/0974-2077.11840

33. Husain TM, Salgado CJ, Mundra LS, et al. Abdominal etching: surgical technique and outcomes. Plast Reconstr Surg 2019; 143(4):10511060. doi:10.1097/PRS.0000000000005486

34. Stephan PJ, Kenkel JM. Updates and advances in liposuction. Aesthet Surg J 2010; 30(1):83-97. doi:10.1177/1090820X10362728

35. Theodorou S, Chia C. Radiofrequency-assisted liposuction for arm contouring: technique under local anesthesia. Plast Reconstr Surg Glob Open 2013; 1(5):e37. doi:10.1097/GOX.0b013e3182a58c80

36. Blum CA, Sasser CG, Kaplan JL. Complications from laser-assisted liposuction performed by noncore practitioners. Aesthetic Plast Surg 2013; 37(5):869-875. doi:10.1007/s00266-013-0153-x

37. Broughton G 2nd, Horton B, Lipschitz A, Kenkel JM, Brown SA Rohrich RJ. Lifestyle outcomes, satisfaction, and attitudes of patients after liposuction: a Dallas experience. Plast Reconstr Surg 2006; 117(6):1738-1749. doi:10.1097/01.prs.0000218986.02861.3f

38. Swanson E. Photographic measurements in 301 cases of liposuction and abdominoplasty reveal fat reduction without redistribution. Plast Reconstr Surg 2012; 130(2):311e-322e. doi:10.1097/PRS.0b013e3182589ef7

39. Gurunluoglu R. Discussion: photographic measurements in 301 cases of liposuction and abdominoplasty reveal fat reduction without redistribution. Plast Reconstr Surg. 2012;130(2):323e-324e. doi:10.1097/PRS.0b013e31825904d8

40. Hawn MT, Houston TK, Campagna EJ, et al. The attributable risk of smoking on surgical complications. Ann Surg 2011; 254(6):914-920. doi:10.1097/SLA.0b013e31822d7f81

41. Sørensen LT, Hørby J, Friis E, Pilsgaard B, Jørgensen T. Smoking as a risk factor for wound healing and infection in breast cancer surgery. Eur J Surg Oncol 2002; 28(8):815-820. doi:10.1053/ejso.2002.1308

42. Xia Y, Zhao J, Cao DS. Safety of lipoabdominoplasty versus abdominoplasty: a systematic review and meta-analysis. Aesthetic Plast Surg 2019; 43(1):167-174. doi:10.1007/s00266-018-1270-3

43. Kaoutzanis C, Gupta V, Winocour J, et al. Cosmetic liposuction: preoperative risk factors, major complication rates, and safety of combined procedures. Aesthet Surg J 2017; 37(6):680-694. doi:10.1093/asj/sjw243 
44. Lin DJ, Wong TT, Ciavarra GA, Kazam JK. Adventures and misadventures in plastic surgery and soft-tissue implants. Radiographics 2017; 37(7):2145-2163. doi:10.1148/rg.2017170090

45. Dixit VV, Wagh MS. Unfavourable outcomes of liposuction and their management. Indian J Plast Surg 2013; 46(2):377-392. doi:10.4103/0970-0358.118617

46. Macias LH, Kwon E, Gould DJ, Spring MA, Stevens WG. Decrease in seroma rate after adopting progressive tension sutures without drains: a single surgery center experience of 451 abdominoplasties over 7 years. Aesthet Surg J 2016; 36(9):1029-1035. doi:10.1093/asj/sjw040

47. Shiffman MA, Di Giuseppe A, eds. Liposuction: Principles and Practice. Springer; 2007.

48. Lehnhardt M, Homann HH, Daigeler A, Hauser J, Palka P, Steinau HU. Major and lethal complications of liposuction: a review of 72 cases in Germany between 1998 and 2002. Plast Reconstr Surg 2008; 121(6):396e-403e. doi:10.1097/PRS.0b013e318170817a

49. Cantu CA, Pavlisko EN. Liposuction-induced fat embolism syndrome: a brief review and postmortem diagnostic approach. Arch Pathol Lab Med 2018; 142(7):871-875. doi:10.5858/arpa.2017-0117-RS

50. Mofid MM, Teitelbaum S, Suissa D. Report on Mortality from Gluteal Fat Grafting: Recommendations from the ASERF Task Force. Aesthet Surg J 2017; 37(7):796-806. doi:10.1093/asj/sjx004

51. Wang HD, Zheng JH, Deng CL, Liu QY, Yang SL. Fat embolism syndromes following liposuction. Aesthetic Plast Surg 2008; 32(5):731736. doi:10.1007/s00266-008-9183-1

52. Mills D, Rubin JP, Saltz R. Fat grafting to the buttocks (Brazilian Butt Lift or "BBL"): urgent warning to surgeons performing fat grafting to the buttocks. Accessed May 12, 2020. https://www.surgery.org/sites/default/files/URGENT-WARNING-TOSURGEONS.pdf

53. Maione L, Vinci V, Klinger M, Klinger FM, Caviggioli F. Autologous fat graft by needle: analysis of complications after 1000 patients. Ann Plast Surg 2015; 74(3):277-280. doi:10.1097/SAP.0000000000000050

54. Triana L, Triana C, Barbato C, Zambrano M. Liposuction: 25 years of experience in 26,259 patients using different devices. Aesthet Surg $J$ 2009; 29(6):509-512. doi:10.1016/j.asj.2009.09.008

55. Chang PY, Wu TL, Tsao KC, Sun CF, Wu LL, Wu JT. Cosmetic liposuc- tion causes only transient elevation of acute inflammatory response and does not advance to oxidative and nitrosative stress. J Clin Lab Anal 2007; 21(6):418-425. doi:10.1002/jcla.20211

56. Giugliano G, Nicoletti G, Grella E, et al. Effect of liposuction on insulin resistance and vascular inflammatory markers in obese women. Br J Plast Surg. 2004;57(3):190-194. doi:10.1016/j.bjps.2003.12.010

57. Grossman JA. Body contouring. Suction-assisted lipolysis and fat transplantation techniques. AORN J 1988; 48(4):713-725. doi:10.1016/s0001-2092(07)69126-1

58. Veber M, Tourasse C, Toussoun G, Moutran M, Mojallal A, Delay E. Radiographic findings after breast augmentation by autologous fat transfer. Plast Reconstr Surg 2011; 127(3):1289-1299. doi:10.1097/PRS.0b013e318205f38f

59. Sailon AM, Wasserburg JR, Kling RR, Pasick CM, Taub PJ. Influence of large-volume liposuction on metabolic and cardiovascular health: a systematic review. Ann Plast Surg 2017; 79(6):623-630. doi:10.1097/SAP.0000000000001195

60. Klein S, Fontana L, Young VL, et al. Absence of an effect of liposuction on insulin action and risk factors for coronary heart disease. $\mathrm{N}$ Engl J Med 2004; 350(25):2549-2557. doi:10.1056/NEJMoa033179

61. Minteer DM, Gusenoff BR, Gusenoff JA. Fat grafting for pedal fat pad atrophy in a 2-year, prospective, randomized, crossover, singlecenter clinical trial. Plast Reconstr Surg 2018; 142(6):862e-871e. doi:10.1097/PRS.0000000000005006

62. Ngaage LM, Wasicek PJ, Puthumana J, et al. A cross-sectional analysis of insurance coverage of extremity contouring after massive weight loss. Ann Plast Surg 2020; 84(3):253-256. doi:10.1097/SAP.0000000000002150

63. Shridharani SM, Broyles JM, Matarasso A. Liposuction devices: technology update. Med Devices (Auckl) 2014; 7:241-251. doi:10.2147/MDER.S47322

64. Kilmer SL, Burns AJ, Zelickson BD. Safety and efficacy of cryolipolysis for non-invasive reduction of submental fat. Lasers Surg Med 2016; 48(1):3-13. doi:10.1002/lsm.22440

Address: Raffi Gurunian, MD, PhD, Department of Plastic Surgery, Dermatology and Plastic Surgery Institute, A60, Cleveland Clinic, 9500 Euclid Avenue, Cleveland, OH 44195; gurunir@ccf.org

\section{Changed your address? Not receiving your copies?}

To receive Cleveland Clinic Journal of Medicine, make sure the American Medical Association has your current information. Cleveland Clinic Journal of Medicine uses the AMA database of physician names and addresses to determine its circulation. All physicians are included in the AMA database, not just members of the AMA. Only YOU can update your data with the AMA.

If your address has changed, send the new information to the AMA. If you send the update by mail, enclose a recent mailing label. Changing your address with the AMA will redirect all of your medically related mailings to the new location.

Be sure the AMA has your current primary specialty and type of practice. This information determines who receives Cleveland Clinic Journal of Medicine.

If you ever notified the AMA that you did not want to receive mail, you will not receive Cleveland Clinic Journal of Medicine. If you wish to reverse that decision, simply notify the AMA, and you will again receive all AMA mailings.

Please allow 6 to 8 weeks for changes to take effect.
To contact the American Medical Association:

PHONE 800-621-8335

FAX 312-464-4880

E-MAIL dpprodjira@ama-assn.org

US MAIL

Send a recent mailing label along with

new information to:

American Medical Association

AMA Plaza

Data Verification Unit

330 N. Wabash Ave., Suite 39300

Chicago, IL 60611-5885 


\section{Liposuction: Concepts, safety, and techniques in body-contouring surgery}

The article in the June 2020 issue by Wu S, photographs of 2 nude patients. The male Coombs DM, Gurunian R (Liposuction: Con- patient's genitals were covered, while the cepts, safety, and techniques in body-con- female patient's were not. The photographs touring surgery. Cleve Clin J Med 2020: 87 have been modifi ed accordingly in the on(6); 367-375; doi: 10.3949/ccjm.87a.19097) line version of the article. We apologize for contained an omission. The article included this oversight. 